\title{
Guest editorial: old masonry under seismic loading
}

\author{
Carlos Sousa Oliveira · Anibal Costa
}

Received: 22 November 2011 / Accepted: 26 November 2011 / Published online: 14 December 2011 (C) Springer Science+Business Media B.V. 2011

Old masonry construction constitutes still nowadays a large portion of the stock of buildings throughout the world. In zones of moderate to strong seismicity, these constructions suffer quite significantly whenever important earthquake events occur.

Due to the above facts, and considering that in many instances these structures are part of the human cultural heritage and require special preservation, a book to mark the 10th Anniversary of the July 9, 1998 Azores Earthquake, which caused a tremendous impact on the housing and religious stocks, was published in 2008. The book, written in Portuguese and entitled "Sismo 1998-Açores. Uma Década Depois" (SPRHI.sa/Governo dos Açores edition), contains a large number of chapters dealing with the various scientific and technical aspects of this earthquake as well as the reconstruction that followed. A PDF version of the book in English should be ready by mid 2012. On the same occasion, an International Seminar on Seismic Risk and Rehabilitation was organized in the City of Horta (Faial, Azores), in July 2008 , to present the main findings described in the book and discuss with the international community the matter of rehabilitation of old masonry construction under seismic loads.

This Special Issue of the Bulletin of Earthquake Engineering collects improved versions of some of the papers presented at the Seminar, complemented with two recent relevant study cases dealing with vulnerability and retrofit, in a total of 15 papers.

The paper by Oliveira et al. describes the most important observations collected after the earthquake that struck the islands of Faial, Pico and São Jorge in July 9, 1998, which constitutes a set of an unprecedented quantity of good quality data about damage in constructions, costs of repair and other variables. A general overview about the impacts of the earthquake on the population, the housing, the monumental structures and on the economy 10 years after the occurrence is also briefly reported and analyzed. This information, assembled in a GIS database, together with similar data obtained from other recent earthquakes, was the base

C. S. Oliveira $(\varangle)$

Instituto Superior Técnico, Lisbon, Portugal e-mail: csoliv@civil.ist.utl.pt

A. Costa

Universidade de Aveiro, Aveiro, Portugal

e-mail: agc@ua.pt 
to construct an overall earthquake impact indicator considering the systemic analysis of the urban area through the identification of a set of criteria and definition of their corresponding descriptors leading to a disruption index (DI). After presenting the methodology leading to the DI, the paper discusses the data which provide a clearer picture about how the systems and their functionality disruption affect an urban area.

The paper by Neves et al. makes (i) a detailed characterisation of the building stock assigning a five category classification; (ii) a detailed damage grade classification based on the different damage mechanisms observed; and, (iii) a seismic vulnerability assessment of the building stock. All the results were integrated into a GIS tool, allowing the spatial visualization of damage scenarios, which is potentially useful for managing seismic risk, from planning emergency response strategies to the definition of retrofitting priorities.

The papers by Carocci and Lagomarsino are dedicated to analyse the effect of the 2009 L/Aquila earthquake on the historical heritage. The paper by Carocci is focused on the illustration of onsite works developed at historical centres struck by the L'Aquila earthquake starting from the first emergency phase. The large number of minor historical centres damaged and the highly differentiated level of damage that occurred implied the need for different procedures to study them. The common goal of these studies is to illustrate the variability of the seismic response of historical masonry buildings when trying to identify both the causes that increased the damage (vulnerabilities) and the factors that limited or prevented it (strengths). The preliminary results allow formulating a first evaluation in view of drawing up reconstruction plans. The paper by Lagomarsino showed the high vulnerability of cultural heritage, with particular reference to churches. Damage assessment in the emergency was carried out on more than 700 churches with a methodology developed after the earthquake in Umbria-Marche (1997) aimed at recognizing the collapse mechanisms in the different architectonic elements of the church. Some examples are presented in this paper, representative of recurrent damage in the main elements of the church: the façade, the roof, the apse and the belfry. It emerges that, for a correct interpretation of damage and vulnerability, a deep knowledge of local construction techniques and of the historic transformation sequence is necessary. Moreover, the bad behaviour of churches strengthened by modern techniques, such as the substitution of original timber roofs with stiff and heavy r.c. slabs, was observed. Starting from the observation of some case studies, the paper achieves some important results, which may be useful for correctly driving future strengthening interventions.

The two papers by Costa et al., one by Proença et al., another by and Pinho et al. are dedicated to experimental testing of either an entire structure or elements of it. The first paper by Costa et al. aims at describing an experimental testing campaign to characterize the out-of-plane behaviour of traditional rubble masonry constructions. Taking advantage of the existence of a two-storey building abandoned after the 1998 Azores earthquake, several in-situ tests were performed with the application of quasi-static cyclic loads at the top level of the building. In addition, the efficiency of retrofitting and/or strengthening techniques applied during the 1998 Azores reconstruction process was also experimentally evaluated. Finally, an overall discussion of these techniques is presented, involving also the results of previous tests carried out by the same authors, in order to infer and suggest the size and the type of strengthening techniques to be used in future interventions on existing buildings. For this purpose, simple analytical mechanical approaches were adopted in order to provide numerical estimates of strength that were found to be in good agreement with the experimental results.

The paper by Proença et al. reports the development of a low intrusion seismic strengthening methodology for traditional masonry structures, which consists in externally applying Glass Fibre Reinforced Polymer (GFRP) composite strips to one or both faces of walls. 
The connection between the GFRP composite strips and the masonry is defined by specifically detailed anchorages or confinement connectors. This technique was tested through an extensive series of experimental tests. This paper focuses on the results of 29 masonry specimens, with different spacing of anchorages, subjected to monotonic and cyclic loading. The results clearly show that the use of anchorages dramatically enhances bond behaviour and that its number and spacing have a significant effect on the deformation capacity, and a less pronounced effect on strength. The paper also provides a calculation model and a ULS safety assessment procedure for out-of-plane strength of reinforced masonry walls, leading to interaction curves.

The second paper by Costa et al. studies the in-plane behaviour of an existing double-leaf stone masonry pier by experimental testing. Additionally, a detailed 3D finite element numerical analysis based on micro-modelling of the original pier is presented aiming at simulating the experimental test results. This numerical strategy can be seen as an alternative way of analysing this type of constructions, particularly useful for laboratory studies, and suitable for the calibration of simplified numerical models. As part of a wider research activity, this work is further complemented with the presentation of an effective retrofit/strengthening technique (reinforced connected plaster) to achieve a significant improvement of its in-plane cyclic response, which is experimentally verified in the results presented.

The paper by Pinho et al. describes and analyses the performance of two structural strengthening solutions for rubble stone masonry walls. One of the solutions consists of sprayed steel reinforced micro-concrete layers on both lateral faces of the walls not in contact with the base of the loading systems, and with transversal steel ties through the thickness of the specimens. The other solution does not have transversal steel ties but has the micro-concrete in contact with the base of the loading systems. Both solutions were tested under axial compression but only the second one under compression-shear loading. Results are then presented and compared with unstrengthened (reference) specimens.

The papers by Arede et al., Silva et al. and Neves et al. deal with the analytical modelling of masonry structures, the first two deal with churches and the third one with a block of 3 -storey buildings. The paper by Arede et al. addresses the development of an integrated strategy for modelling, experimental calibration, numerical analysis and seismic strengthening carried out in the Bandeiras and Madalena churches located in the Pico Island, Azores. Following an initial description of the observed damages resulting from the 1998 earthquake, the modelling option for the churches' structures is outlined. Ambient vibration tests were used for identification of frequencies and mode shapes which were then compared to the numerical ones for calibration purposes. Seismic analyses were carried out using the records of the 1998 earthquake and the obtained results were analysed in light of the real observed damages. Numerical findings were then used to support proposals for seismic strengthening of these churches.

The paper by Silva et al. deals with the evaluating the capacity of a non linear continuum damage model, originally developed for concrete structures, to simulate the behaviour of stone masonry structures. In particular, the seismic response of an old stone masonry construction, the Gondar church, is analysed considering different levels of geometrical and material complexity. The verification and calibration procedures make use of the experimental results from laboratory tests performed on stone masonry walls and from other tests reported in the literature. The results are compared, assessing the differences and the importance of using complex tools, such as the continuum damage model, to better simulate and understand the global behaviour of such constructions.

The paper by Neves et al. addresses the study of the seismic response of an urban building block located in the City of Horta. The work fits within the framework of studying 
strengthening schemes suitable for the reconstruction process of a town damaged by an earthquake, and includes the numerical modelling of all the buildings in a block with calibration of material and structural parameters based on ambient vibration tests. The study aims to understand a number of issues that are likely to influence the global behaviour of the block and the local response of individual buildings, namely the effect of adjacent constructions, the in-plane stiffness of floors and/or roofs and the presence of possible localized strengthening interventions in selected parts of the block.

The paper by Nakagawa et al. reports the dynamic collapse test of a $3 \mathrm{~m} \times 3 \mathrm{~m} \times 3 \mathrm{~m}$ brick masonry house constructed with Pakistani bricks carried out on a one-direction horizontal large-scale shaking table. The authors applied a new numerical simulating method based on the Extended Distinct Element Method (EDEM) and conducted collapse simulations of the brick masonry house behaviour during the shaking table tests. In the numerical simulation model, bricks were assumed to be rigid bodies, and mortar was modelled using a mortar spring that consists of a normal spring and a shear spring. The parameters of each mortar spring were defined based on the results of material tests. Simulated results showed various collapsing processes, and the simulated aspects were found to be similar to the results of the shaking table tests.

The papers by $\mathrm{D}^{\prime}$ Ayala et al., Hancilar et al. and Pujades et al. refer to vulnerability studies of historical buildings in Istanbul (the first two) and of a typical district in Barcelona (the last). The paper by $\mathrm{D}^{\prime}$ Ayala and Ansal deals with the objectives of the Istanbul Seismic Risk Mitigation and Emergency Preparedness Project to improve Istanbul's preparedness for a potential earthquake. In this study, 170 historical buildings with global cultural heritage value were selected for vulnerability and risk assessment. Discussion of the choice of the most appropriate earthquake scenario, including the effects of local site conditions on the seismic performance, on the procedure to obtain the capacity curves to achieve the most appropriate level of ductility, and on the equivalent reduction coefficient are made. A procedure to evaluate performance points and to define safety factors based on lateral acceleration, drift or expected damage level, is presented. The process of arriving at a risk value and, therefore, at recommendations for strengthening or otherwise, is finally highlighted with respect to two comparable case studies.

The paper by Hancilar et al. describes the earthquake performance assessment of two historical buildings located in Istanbul exposed to a $\mathrm{Mw}=7+$ earthquake that is expected to hit the city and proposes solutions for their structural rehabilitation and/or strengthening. Both buildings are unreinforced clay brick masonry (URM) structures built in 1869 and 1885 , respectively. The first building is a rectangular-shaped structure rising on four floors. The second one is L-shaped with one basement and three normal floors above ground. They survived the $1894 \mathrm{Ms}=7.0$ Istanbul Earthquake, during which widespread damage to URM buildings took place in the city. Earthquake scenarios are determined through probabilistic and deterministic seismic hazard assessment. Strength characteristics of the brick walls are assessed on the basis of Schmidt hammer test results and information reported in the literature. Dynamic properties of the buildings (fundamental vibration periods) are measured via ambient vibration tests. The buildings are modelled and analyzed as a three-dimensional assembly of finite elements. Following the preliminary assessment based on the equivalent earthquake loads method, the dynamic analysis procedure of FEMA 356 and ASCE 41-06 is followed to obtain the dynamic structural response of the buildings and to evaluate their earthquake performance. In order to improve earthquake resistance of the buildings, reinforced cement jacketing of the main load carrying walls and application of fiber reinforced polymer bands to the secondary walls are proposed. 
The paper by Pujades et al. describes the seismic performance of a block of buildings from the Eixample district of Barcelona. These unreinforced masonry buildings were constructed in the late nineteenth and early twentieth centuries, and they are currently still being used as dwellings. Although they were built individually, these buildings are connected to the adjacent buildings, forming blocks composed of aggregates. In order to analyze the seismic behaviour of isolated buildings and aggregates, two typical central buildings and one typical corner building have been chosen. Standard pushover analyses lead to evaluate their seismic performance by means of capacity spectra and fragility curves. Two earthquake scenarios including soil effects are considered. The first one is a deterministic historical earthquake scenario based on a real earthquake that occurred in 1824, $25 \mathrm{~km}$ away from the city, and the second one is a probabilistic scenario based on 475 years return period.

The mean damage grade is 2.3 for the deterministic scenario and 2.7 for the probabilistic one. This means that moderate to severe damage is expected in both cases. Furthermore, in the case of the deterministic scenario, more than $10 \%$ of the buildings would suffer extensive-to-collapse damage and nearly $20 \%$ for the probabilistic scenario, which confirms the high vulnerability of such buildings.

As Guest Editors of this special issue of the journal, we would like to sincerely thank the authors and the international panel of reviewers for all the submissions which made the publication of this Special Issue possible. Also, we would like to specially thank the Editor of the Bulletin of Earthquake Engineering, Prof. Atilla Ansal, for all the support, and also the technical staff of Springer for the assistance provided. 